\title{
CATALYST
}

feminism, theory, technoscience

\section{How Can You Spell Care with Only 1s and os?}

\author{
Romi Ron Morrison \\ University of Southern California \\ Morro52@usc.edu \\ Loren Britton \\ hello@lorenbritton.com
}

\section{Keywords}

practice, feel, mutual aid, scale, noticing, disability, notation, archive, ritual, computation, programmability, quilts, preparation, Black, measurability, materiality, relationship

\section{Ritual for Reading}

Be with this text on your computer, smartphone, tablet, piece of paper or whatever other device and pause for a moment. Take the chance to feel the humming of your processor, the ink on the page, the brightness of the screen and the contrast (or not) from this text with your surrounding environment. Choose how you want to enter into the text, will you sit? Lie down? Read out loud? Have the text read to you? Consider if you need a sip of something wet, check in with your body and when ready - begin.

What follows is a conversation between artists and scholars Romi Ron Morrison and Loren Britton who have become friends since they met right before the Covid-19 pandemic. During this time of distance in space and time they have found themselves in multiple conversations over questions of who gets to have a life in the computational presents we are enmeshed within. Their shared interests lie in moments of everyday noticing, attention, and community processes that

Morrison, Romi Ron and Loren Britton. 2021. "How can you spell care with only 1s and os?"

Catalyst: Feminism, Theory, Technoscience 7 (2): 1-14.

http://www.catalystjournal.org|ISSN: 2380-3312

(c) Romi Ron Morrison and Loren Britton. 2021 | Licensed to the Catalyst Project under a Creative 
form the capacity for greater resistance against algorithmic normalizations that continually foreclose life chances for those most vulnerable.

Recently they have collaborated on the web plugin Soundings that is an invitation to willfully interrupt web browsing, and slow down. Both Morrison and Britton are members in the collaborative oracle(s) with Helen Pritchard and Eric Snodgrass, which is a practice of developing poetic technologies that might free ourselves from the computational practices of measurement, categorization, extraction and optimization.

In this conversation there are interruptions by different emojis that pop into the text to introduce references or extra associations for our readers. These interruptions use emojis from Mutant.Tech that work towards an open source and more diverse emoji future.

("Infinity". Emoji description: A black and white emoji that is like the number ' 8 ' turned sideways to signal "infinity".) This comes up when we reference an idea directly from a scholar or artist.

\section{9.}

("Moon Viewing Ceremony". Emoji description: A moon in the top right part of the emoji shines over a triangle and some plants.) This comes up when we have a little extra association or lagniappe.

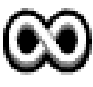

Dzuk. Mutant Standard. 2017 - 2020. Accessed 29 July 2021. https://mutant.tech/.

Britton, L., Morrison, R., Pritchard, H., and Snodgrass, E. 2020. oracle(s) - becoming undone together. Accessed 29 July 2021. https://vimeo.com/441452535.

Morrison, Romi Ron and Loren Britton. 2020. Soundings. Accessed 29 July 2021. https://altcph.dk/soundings-romi-ronmorrison-loren-britton/.

Loren Britton (LB): Maybe there's no right way to start so I'll pick up and begin. In other writings of yours you have spoken about a re-imagination of programmability that would remake computing towards Black Computational Thought, a term you are developing that refuses computing that stems from white western modernity as its sole archive. In this writing you talk about social formations that exceed measurability and separable difference and stay with proximity, shared risk, accountability and receptivity. I wanted to ask you about what examples you work with that might speak to these computational moments that exceed measurability? I thought this might be a chance to talk about your 
project engaging the Freedom Quilts as well as the work you are currently developing for Transmediale that is called Noticing the Preconditions for

Silva, Denise Ferreira da. 2016. "On Difference Without Separability." 32nd Bienal De São Paulo Art Biennial: Incerteza viva: 5765.

Chen, Nancy N. 1992. "'Speaking nearby': A conversation with Trinh T. Minh-ha." Visual Anthropology Review 8 (1): 82-91. https://doi.org/10.1525/var.1992.8.1.82.

18.

Accountability reminds me of the entry, Dreaming Accountability, from Mia Mingus on her blog, Leaving Evidence, that reads "What if accountability wasn't scary? It will never be easy or comfortable, but what if it wasn't scary? What if our own accountability wasn't something we ran from, but something we ran towards and desired, appreciated, held as sacred?"In the context of our conversation here we discuss amongst other things where our sacred accountabilities lie, and how we can develop ways of caring for ourselves and these practices as we make and unmake technoscience.

Mingus, Mia. Leaving Evidence. "Dreaming Accountability," 5 May 2019. Accessed 29 July 2021.

https://leavingevidence.wordpress.com/2019/05/05/dreamingaccountability-dreaming-a-returning-to-ourselves-and-each-other/.

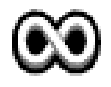

Morrison, Romi Ron \& Mimi Onuoha. 2021. Noticing the Preconditions for . Transmediale. Accessed 20 July 2021. https://transmediale.de/almanac/noticing-the-preconditions-for_.

Romi Ron Morrison (RRM): I want to start by acknowledging that I appreciate the ways that you're attending to my interest in programmability particularly as a way to get towards this concept of Black Computational Thought, which feels like a practice of recovering these instances that just often aren't seen as being relevant to computation. I'm really trying to push beyond an acceptance of computation, programmability, software, data, measurement-these things that have become so standard within the lexicon of computation, as self-evident and transparent. Instead, I want to understand the much longer, historical, and residual baggage these practices carry due to the violences they inherit from Post-Enlightenment scientific thought.

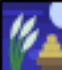

Here I am using transparent akin to the transparent I evoked in Silva, Denise Ferreira da. 2007. Toward a Global Idea of Race.

Minneapolis, MI: University of Minnesota Press. 
For a deeper dive into the ways that colonial violences structure scientific thought see Wynter, Sylvia. 2003. "Unsettling the coloniality of being/power/truth/freedom: Towards the human, after man, its overrepresentation-an argument." New Centennial Review 3 (3): 257337. https://doi.org/10.1353/ncr.2004.0015.

So for me, the practice of returning to certain social practices, formations and social technical infrastructures that arise out of Black diasporic movement is an attempt to think about these terms very differently. I believe that these instantiations of Black technical practice begin to illustrate the contours for what a space might look like that is adverse to but subtends the totalizing residue of colonization and Post-Enlightenment scientific discourse.

18 I am thinking about residue alongside Lisa Lowe's work on the residual, borrowing from Raymond Williams in Lowe, Lisa. 2015. The Intimacies of Four Continents. Durham, NC: Duke University Press.

I'm looking for examples in which people have contended with concepts like measurability or data on very different grounds and so the Negro Motorist Green Book, as a collection of safe places for traveling Black people to access, is an example of a kind of cybernetic system that doesn't mirror the automated control that can be found in Norbert Wiener's imaginary about how a city should function.

Green, Victor H., 1936 - 1967. The Green Book. New York, NY:

Victor H. Green \& Company. Accessed 29 July 2021.

https://digitalcollections.nypl.org/collections/the-greenbook\#/?tab=about\&scroll=10.

In some of the unpublished writings that I shared with you there's a whole essay about Jennifer Light's brilliant work charting the use of military technologies for municipal use. She helps me understand how immensely rewritten American cities became within pervasive cybernetic logics of management in the face of Cold War inspired threat, particularly Black urban rebellions from 1965-1969. So, for me I'm looking at a dialectic for how Blackness produces other types of technologies, not just those that are about capture and control, and The Negro Motorist Green Book as a site of cybernetic operation opens itself for there to be dialogue about trust, and emphasizes the face to face encounters of people making decisions together within a system that still circulates, and is about information flow. Something gets lost or foreclosed when the emphasis is only on optimization and automation. What's fascinating to me about the Green Book are the ways in which the information is sourced, compiled, and then circulated through Victor and Alma Green's social relationships within the U.S. Postal 
Workers Union. By having postal workers literally walking their routes, engaging with neighbors, and having relationships with business owners, they would note safe places for Black people, send them to Victor and Alma Green who would compile them and circulate them back out as destinations in the Green Book. Even at the end of every printing of the Green Book there's always a call for more destinations to be added, so it works as a crowdsourced directory that is explicitly about the preservation of Black life across space that is not a neutral container, but is overtly hostile.

RRM: And I think there's also something interesting about this context because the operations are not transparent. The Negro Motorist Green Book isn't written as a survival guide for Jim Crow or white supremacy it's written innocuously as a travel companion. This is a form that engages with different types of opacity that can be productive and necessary. It also complicates these cybernetic operations by foregrounding how people are engaged in shared risk in a way that doesn't remove the flesh and allows for a kind of presence with each other. This emphasis on shared risk and flesh expands the ways that I want to think about programmability, as an engagement, albeit often unequal, that can hold different power relations allowing people to step into other ways of becoming together. I'm trying to think about programmability in that sense, rather than accept the master slave logic within computation, or the determinism of programmability that Wendy Chun has traced to Mendelian genetics and American eugenicists.

10

These thoughts on programmability and shared risk are informed by Zakiyyah Iman Jackson's work on symbiosis in Becoming Human: Matter and Meaning in an Antiblack World.

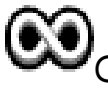
Chun, Wendy Hui Kyong. 2011. Programmed Visions: Software and Memory. Cambridge, MA: MIT Press.

Jackson, Zakiyyah Iman. 2020. Becoming Human: Matter and Meaning in an Antiblack World. New York, NY: NYU Press.

LB: In your work on the Freedom Quilts which were quilts carefully constructed and stitched to direct fugitive Black people escaping slavery in the US South towards freedom; you have written about the quilting bees on plantations where the language, pattern, stitching and constant reformulation / modulation of these quilts would be re-inscribed through their community production. In this way these quilts are highly specific, contextual land cues, a culturally situated practice towards freedom. I wonder if you want to say more about this, also perhaps on the relation of the materiality of these quilts to the land that they were present on? 
120

These practices of language, patterning, contextual specificity and slippage relate to a project I have worked on with my collaborator Isabel Paehr called Hacking Concrete. This work engages material instability to make concrete 'open' even though it is often a material that can foreclose access to spaces and colloquially is understood to be solidified.

MELT (Loren Britton \& Isabel Paehr). 2021. Meltionary. "Hacking Concrete." Accessed 29 July 2021. http://meltionary.com/hackingconcrete/start.html.

RRM: Yeah, so this is really becoming important and crucial for me, this practice of trying to hold the productive tension of seemingly disparate things togetherwhich reads like an autobiography at this point. My relation to scholarship begins within Black Studies and Gender Studies, centering Queer Black Feminist Theory in particular, and then extended to experimental practices of design, architecture, and geography. And I now carry those practices through to consider the effects of computation on the production of space while still reading from a Queer Black Feminist lens. This allows me to interrogate and denaturalize certain computational practices as self-evident or already fully understood.

I'm trying to better understand the ways that theories of computation, which are never fully deracinated or separate from Post Enlightenment thoughts of empiricism, measurability, or calculation, have a huge effect on how we understand land and space. Both in the managing and organizing of space but more importantly in the types of spatial imaginaries that computational logics allow. Jennifer Light's book From Warfare to Welfare: Defense Intellectuals and Urban Problems in Cold War America does a great job of this. It shows the ways that military actors like the RAND Corporation, essentially trying to diversify their bottom line, introduce certain computational informatics and cybernetic architectures into municipal governments. There is a clear way in which the city as a whole is being reimagined from the 1950 s to the 1970s through large scale logistics management, urban planning, data capture, and predictive analytics.

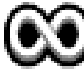
Light, Jennifer. From Warfare to Welfare: Defense Intellectuals and Urban Problems in Cold War America. Baltimore, MD: John Hopkins University Press.

So I want to pay attention to how modern ideas about measurability, control, and conquest inform cybernetics as a new science of management, and produce specific typologies of urban space. Alternately, The Negro Motorist Green Book and the Freedom Quilts as Black technological practices produce different spatial and computational logics. So I'm deeply curious about the Black production of 
space and technology that come from things like The Negro Motorist Green Book and the Freedom Quilts. Coming back to your question about the Freedom Quilts, the locations of the quilting bees on plantations are essential sources for information gathering that have a great deal of geographical and topographical specificity because people are literally having to navigate the landscape in order to then tell others about what resources they might find and encode that data through detailed stitching patterns. These patterns and ties were also used to plot mile markers so that people can plan how far they can travel within a day.

Maintaining this contextual basis for place expands computation beyond the glossy and frictionless descriptions often assigned to it where we simply input and output information, but stays with the troubled materiality in which computation is co-constituted through the specificity of place, social engagements and shared agreements. This approach to computation is sociogenic and gives a broader understanding for how computation is constituted otherwise at different times, by different people, in different places. And so I try to hold on to these instantiations because I think they're particularly helpful now, as we're trying to engage in rich critical discourse about computation and violence, and rather than trying to speak to the violences within the same language that has given birth to them, I'm trying to find these other lexicons or dialogues because I think they are a lot more expansive.

Wynter, Sylvia. 2013. "Towards the Sociogenic Principle: Fanon, identity, the puzzle of conscious experience, and what it is like to be 'black'." National Identities and Socio-Political Changes in Latin

America, 46-82. https://doi.org/10.4324/9781315052717-8.

LB: Totally. I am taking note of the stitching patterns and the materiality of these quilts as socio-technical objects, the patterns or ties for example that would signal distance. These questions of materiality, spatial relationships and the capacity for negotiation towards movements towards freedom reminds me of my work as MELT with Isabel Paehr on a project called Rituals Against Barriers. In this project we have been developing ritual and material based experiments that are inspired by practices of survival in oppressive contexts and take the form of ritual practice. We think about how rituals can invite movements away from normativities and can allow entry into practices like refusing to ignore a feeling, refusing ableist spaces, and refusing to speed up even if that is the normalized tempo. In that work, rituals are moments of joy, of refusal, collective practice, of uncomfort and unlearning.

四 Although in this work rituals are upheld as a space for practicing towards liberation and pushing back against ritualized oppressions, we also attend to the ways in which oppression becomes normalized by dominant and oppressive culture. In her book Dark Matters: On the 
Surveillance of Blackness, Simone Browne points to "the ritualized practices and trauma of white supremacy" (105) which is another kind of structural violence which must be refused.

Browne, Simone. 2015. Dark Matters: On the Surveillance of Blackness. Durham, NC: Duke University Press.

MELT (Loren Britton \& Isabel Paehr). 2021. Meltionary. "Rituals Against Barriers." Accessed 29 July 2021. http://www.meltionary.com/meltries/a.html.

We have been looking into the history, present, possibilities and devastating failures of disability justice/activism within the United States and in Germany. We have thought a lot about these entanglements of place, space, access and technology nearby Aimi Hamraie in their book Building Access: Universal Design and the Politics of Disability. In the chapter, Sloped Technoscience, they tell the story of how disabled people and their accomplices drove around in Berkeley, California in the 1970 s and took sledgehammers to inaccessible streets in order to crumble curbs, repour cement and physically make the streets more accessible. Reflecting on this history, they ask: "If we take a sledgehammer to the seemingly concretized sidewalks of disability rights history, what layered sedimentations of resistance do we find below? (Hamraie, 103)". They share images of concrete pieces that are artifacts or evidence of hacking the city and making material interventions towards other more accessible worlds. It's an example from a different archive, but it resonates with how the materials of socio-technical systems say so much about their context, like you were talking about.

\section{9.}

A Ritual from Rituals Against Barriers: Ritual for tending to the "not perceivable": From Undrowned by Alexis Pauline Gumbs, spend time with the question: "What becomes possible when we are immersed in the queerness of forms of life that dominant systems cannot chart, reward or even understand?"

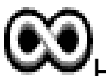

Hamraie, Aimi. 2017. Building Access: Universal Design and the Politics of Disability. Minneapolis, MI: University of Minnesota Press.

Gumbs, Alexis Pauline. 2020. Undrowned: Black Feminist Lessons from Marine Mammals. Chico, CA: AK Press.

RRM: Yeah, absolutely. It makes me think about a few things. There's a way in which Ruth Wilson Gilmore describes abolition as a radical presence, and I think that has a lot of relevancy here. Especially the power and devastation that certain imaginaries concretize. Which is why the hack is super enticing and provocative, and also attuned to a close proximity for understanding needs and desire. Urban 
planning and programming don't often come out of histories in which they're anticipating that people will imbue new uses within their creations, the master plan is not something that's very adaptable because it's setting 10-year goals linearly into the future that are self-contained. What is imagined in the abstract as ideal or commonsensical becomes written, codified, and then materialized. And practices of urban design and software design both tend to imagine ideal universal users. What's so lovely about the materiality in your example is that it breaks this imagined standard and forces a kind of focus around quotidian daily practices, even rituals, that are about what it means to notice your own desires and needs, and then to be poised to take the sledgehammer and edit the curb. This is not arbitrary, it's not a random act of destruction, it is considered and is indeed a relationship to place. When I'm trying to search for examples that practice computation on different grounds they almost always exhibit that kind of everyday attentiveness to refute the universalizing claims of computation as a transcendent cloud.

Gilmore, Ruth Wilson. 2007. Golden Gulag: Prisons, Surplus, Crisis, and Opposition in Globalizing California. Oakland, CA: University of California Press.

Instead I'm trying to stay in the dirt and the soil, walking the ground. So thinking about the curb edits, the postal workers walking their daily routes, the plantation grapevine that then feeds information to quilting bees, they are practices that engage the materiality of shared risk to intervene in everyday desires in excess of the present.

LB: Yes exactly, it reminds me of a quote from Remi M. Yergeau that "Bodies are not for hacking, bigotry is.!" So, I understand your work on Rituals of Black Fugitivity: directly picks up on practices of ritual as they meet Black diasporic practices and I wonder if you want to speak more to this? As I've thought about them, rituals have been about accessibility creating practices, so rituals are something that can be enacted in community or alone that enact the possibility of a specific sense of space within uninhabitable conditions.

Yergeau, Remi M. 2014. "Disability Hacktivism." Hacking the Classroom: Eight Perspectives, edited by Jentery Seyers \& Mary Hocks. Last accessed 29 July 2021. http://web.uvic.ca/ jentery/hacking/. Morrison, Romi Ron. 2018. "Rituals of Black Fugitivity:." Accessed 29 July 2021. https://elegantcollisions.com/rituals-of-blackfugativity-p. 
RRM: For me ritual is a very spatial-temporal relationship. Before sitting in front of my altar, talking to ancestors, or writing I need to prepare myself and my space. I can't sit in front of my altar if my room is messy, or I haven't washed my face yet. The preparation and the making of space is part of the ritual. It becomes vital to prepare the space to be ready for the ritual to show me what it needs to show me, otherwise I'm not engaged in ritual. So, there's a kind of preparation for me, that's a part of ritual that in turn produces its own space-time.

LB: I mean, yeah. I really appreciate the way that you come back to preparation. The distinction between habit and ritual is something that I've been considering as well, when is something pathologized and when not, who decides? What are the stakes of the amount of preparation that must be enacted in order to withstand great precarity? And who has access to that time, space, resources, and community practice to be well prepared?

These practices that affirm agency remind me of Rosemarie Garland-Thomson's concept of misfitting as a shifting spatial and temporal relationship that affirms the agency and value of disabled peoples' experiences. She discusses how misfitting avoids genericizing disabled experience and undoes myths around dependency/ interdependency. Misfitting time-space-experience could then be a way to move within and care for our brilliant knowledges and challenge worlds that were not built for us. Thinking about sensory experiences, there are quite some preparations needed to withstand, or to find ways to be okay in shifting contexts that are specific to my body-mind. I very much relate to what you're saying.

Bodymind is a materialist feminist disability studies concept from Margaret Price and has been taken up by multiple disability studies scholars to discuss the enmeshment of the body and mind which have been constructed as separate due to Cartesian dualisms of western philosophy. Theorists I follow who engage this concept include: Margaret Price, Sami Schalk and Aimi Hamraie.

Price, Margaret. 2015. "The Bodymind Problem and the Possibilities of Pain". Hypatia, 30 (1): 268-284. https://doi.org/10.1111/hypa.12127; Schalk, Sami. 2020. Bodyminds Reimagined: (Dis)ability, Race, and Gender in Black Women's Speculative Fiction. Durham: NC: Duke University Press.; GarlandThomson, Rosemarie. 2011. "Misfits: A feminist materialist disability concept". Hypatia 26 (3): 591-6o9. http://doi.org/10.1111/j.15272001.2011.01206.x.

RRM: Yeah I definitely feel that, even in things that we understand to be really phenomenological or stochastic, like improvisation within jazz music or 
polyrhythmic West African drumming ensembles. There is this great conversation between Arthur Jafa and Steve Coleman and they're speaking about jazz and this misnomer in which people assume improvisation is just pure unbridled creation and that you start from nothing, and it's like no there is so much preparation that goes into constantly playing a scale over and over again so that your approach to the scale becomes instinctual. You're trying to build an instinctual muscle memory for having a lot of notes at your disposal to play with. But the actual improvisation isn't just an act of randomization; it's an act of preparation that allows for expansive forms of emergence to happen. That feels very akin to me when thinking about ritual to respond to precarity that is not about prediction. Because prediction is about trying to eliminate flux, change, and what can't be conceived at the time. It is about the limiting of options and limiting the ability of other options to arrive. I think Kara Keeling speaks to that really well in Queer Times Black Futures. Specifically, in corporate futures planning...

Keeling, Kara. 2019. Queer Times Black Futures. New York, NY: NYU Press.

Jafa, Arthur. 2018. "Love is the Message: An Evening with Arthur Jafa." Accessed 30 July 2021.

https://www.youtube.com/watch?v=yOYd IAPleo.

LB: Talking about Shell I think.

RRM: Right! And I love the ways that she is bringing in thoughts on antifragility and practices within Black life that are made to be inherently antifragile, the ways that she talks about James Snead's work on repetition, modulation, coverage, and the cut, as ways to build accidents into the process and repetition as that kind of preparation, the ability to return to the altar to make space for feeling composed enough to meet the precarity or unpredictability of the day rather than attempting to map out any potential threat at the beginning of the day and then avoid them as much as possible. There is a very different gesture there. So I think there is a lot here to consider towards Black Computational Thought that invites ritual practice rather than prediction when trying to mitigate risk by making space for it as a relation.

James Snead, "Repetition as a Figure of Black Culture," in Black Literature and Literary Theory, ed. Henry Louis Gates and Sunday Ogbonna Anozie (New York; Routledge, 1984), 59.

LB: So, relatedly, we read together many great texts in prep for our conversation, like Michelle Murphy who talks about phantasmagrams. Phantasmagrams as Murphy introduces them are about the affective or emotional attachment to 
enumeration or the emotional quality of numeracy and all of the things that fall outside of numbers themselves that are relatable. In her text she talks about Gross Domestic Product (GDP) and care labor that is excluded from the GDP. I'm curious about your interest in phantasmagrams as expressions of the excess of numeracy as they sit alongside Black Computational Thought? Do you see these as being in relation?

$\infty$ Murphy, Michelle. 2017. The Economization of Life. Durham, NC: Duke University Press.

RRM: Yeah, so I think phatasmagrams allows for me to bring in certain forms of Black Studies scholarship that would maybe otherwise be seen as really outside the bounds of any theory of computation or data. I'm hesitant to make a parallel between phantasmagrams and Black Computational Thought even though I think there are some shared components. This relationship to numeracy and what lives in excess of the digit as well as our attachments to them, are both components where there is a shared investment between how Michelle Murphy is talking about phantasmagrams and how I am trying to think about Black Computational Thought. So what phantasmagrams do for me is they speak to the often removed affective attachment to a metric. Often critiques of big data or algorithmic bias is about "oh these just aren't the right numbers, or these aren't the right inputs and that's why we're getting bad junk data out" it still treats the numeral, the integer, as if it is just a cold quantifiable thing. It's just computed, it's not something that we also have this libidinal attachment to. So what I like about Michelle Murphy's text is that, she's looking at things like the rise of population and its relation to GPD in this post Malthisian natural scarcity world and is really explicitly talking about the forms of violence that then become justified because of this affective attachment to GDP as an indicator of the literal health or potential progress of the nation. So, it is a really provocative example to bring up the affective attachment to numbers or enumeration, particularly at a large scale when talking about population or GDP as nascent concepts for nation building.

So, for me that is really helpful when looking back at Jennifer Light's work. Light details how so many cybernetic interventions that happened within municipalities failed in terms of making cities more efficient. She notes how technicians acknowledged their failures, but the affective attachment to the imaginary of control over large urban processes still overwrote that recognition of failure. So phantasmagrams are really important because they speak to the affective attachment to enumeration as fact or truth. That is really useful for intervening in critiques of technology and opens the space for me to bring in the work of scholars like Sylvia Wynter and talk about sociogeny and the ways in which storytelling, language, and the imaginary are not separate from what we think of as empirical, scientific, or measurable. It is a hybrid. This situates computation so that we can tell different stories about it. 
LB: I had a question about forms of attention and sensemaking, that might be related to other stories we could tell about computing, we talked already about modulation or vibration. And I'm curious to think with you about other sorts of sense-based practices like smell or things that exceed the written, which seems like something that you might be interested in, but we didn't directly talk about. It's also something I'm quite interested in. And then I also had a question about scale, which is maybe a different direction.

RRM: This project that I've been working on with Mimi Onuoha for Transmediale is pretty explicitly about a kind of sensemaking, which we've been talking about as noticing. For us, noticing is about giving a lot of attention to small, very ordinary things that hold a lot of potential. And that can be instructive for recognizing a desire for how we might want to live or be together, that's not always allowable in the present.
Q12
Here I am thinking with José Muñoz's work in Cruising Utopia: The Then and There of Queer Futurity in which desire is essential for reaching towards the horizon of queer futurity. Desire becomes a manner of knowledge to seek what may not be allowable now but needs to exist. It is a practice of beginning to conjure.

And so the content is essentially all about a particular form of sensemaking. And a sensemaking for paying attention to what otherwise might fall out of memory. In particular, Mimi and I both share a kind of investment in Blackness as a political analytic to frame the things that we notice. Repetition and ritual return here to be able to meet risk from a different vantage, it's not about prediction, but it's about building up a practice of making space for what can be accounted for. So in this piece we each separately notice an expression of care from our daily lives, document it, and make an interpretation of it in the form of a short media work. Then through the act of correspondence we share those works with each other to iterate upon them, and then send it back to repeat again. So that, that original thing is occluded, but what we get instead are different permutations based on interpretation. It makes interpretation an explicit part of data collection and also includes my relationship with Mimi as an important part of that interpretation. It is relational. This kind of shared correspondence reminds us of the things that a single person can't hold within their attention and is an attempt to recognize the value in building relational forms of sensemaking.

LB: Yes, definitely. I like how you and I in our practices make sensemaking at different scales. There must be structural change but also there are ways in which change is made every day. I don't know if you know the collective called SINS INVALID? They're based in California. I'm a huge fan of their work, they are a BIPOC led Disability Justice collective, and they center disabled people focusing 
as they say on "An Unashamed Claim to Beauty in the Face of Invisibility". They share a lot of resources about disability justice on their website and have many performances also online to view. They have this amazing podcast titled "Into the Crip Universe" that explores the intersection of disability justice and climate chaos. In this podcast Patty Berne, one of the founders of Disability Justice, talks about all the ways that in the midst of climate chaos the kind of support that might be needed. In the episode, "We Love like Barnacles", Berne poses the question "When climate disaster strikes, will able-bodied allies be there for us?". She goes on to consider what kinds of small mutual aid we might need to practice like: having a text message group to check in, sharing fridge space and making sure that people have access to their meds. These small scale mutual aid initiatives really create access for people right because when we're talking about accessibility, we know that we can't always rely on larger structures to care for us so we practice caring for each other.

SINS INVALID: Into the Crip Universe Podcast Episode 1. "We Love like Barnacles." 2020. Accessed 29 July 2021.

https://www.sinsinvalid.org/podcast/2020/10/16/episode-1foundations-of-climate-justice-and-disability-justice.

\section{Ritual for Closing}

Allow these words to wash over you. Release the pressure to capture them and stow them away. Instead allow yourself to be a sieve. Give attention to what bubbles up. Those errant turbidities that collect in patches. These are the beginnings for new ground. Moving takes practice and we begin with a question. What if we cared for each other with an ease that holds shared risk?

\section{Author Bios}

Romi Ron Morrison is a Black queer non-binary artist, researcher, and educator. Their work investigates the personal, political, ideological, and spatial boundaries of race, ethics, and social infrastructure within digital technologies. Using maps, data, sound, performance, and video, their installations center Black Feminist technologies that challenge the demands of an increasingly quantified world-reducing land into property, people into digits, and knowledge into data.

Loren Britton is a white trans* interdisciplinary artist and researcher tuning with practices of Critical Pedagogy, Trans*FeministTechnoScience and Disability Justice. Engaging the queer potential of undoing norms they practice joyful accountability to matters of collaboration, computing, trans*gender politics, Black Feminisms, and transformations. They love slowness, reading out loud, following non-linear processes and experimenting towards greater accessibility. 